\title{
Worker Flows, Job Flows and Unemployment in a Matching Model
}

Simon Burgess

Hélène Turon

Discussion Paper No. 05/572

January 2005

Department of Economics

University of Bristol

8 Woodland Road

Bristol BS8 1TN 


\title{
Worker Flows, Job Flows and Unemployment in a Matching Model $^{*}$
}

\author{
Simon Burgess ${ }^{\dagger}$ and Hélène Turon ${ }^{\ddagger}$ \\ J anuary 2005
}

\begin{abstract}
Standard matching models of unemployment assume that workers and job flows are identical. This is in stark contrast to empirical evidence that job flows in fact only account for a fraction of worker flows, that unemployment exits only account for a fraction of hires and that these fractions vary over the cycle. In this paper, we develop and calibrate a model based on the Mortensen and Pissarides approach but that emphasises this issue. We show that this matters - that it has very different implications for our view of unemployment dynamics.

The key features of our model relate to the search options of the worker, and the job creation decision by firms. We allow workers to search whilst employed, and firms to re-advertise jobs that have been quit from. This leads us to use a different job creation process, whereby potential vacancies, or job 'ideas', arise at a finite rate per period over a range of idiosyncratic productivities. In the standard setting, there is an unlimited supply of potential vacancies at the top idiosyncratic productivity.

The main results are as follows. First, the presence of on-the-job search has a substantial impact on labour market equilibrium, whereby equilib-
\end{abstract}

${ }^{*}$ An earlier version of this paper was called "Unemployment equilibrium and on-the-job search".

†University of Bristol, CEPR and IZA.

$\ddagger$ University of Bristol and IZA. Corresponding author: Helene.TuronLacarrieu@bristol.ac.uk. Department of Economics, University of Bristol, 8 Woodland Road, Bristol BS81TN. We would like to acknowledge financial support from the European Union for the DAEUP CEPR network and from the Leverhulme Trust for Helene's Special Research Fellowship. We are grateful to Sonia Bhalotra, David de Meza, Christian Heafke, Fabien Postel-Vinay, Marisa Ratto, Silvia Sonderegger and seminar participants at the DAEUP, Royal Economic Society, EEA and EALE conferences, at the IZA/SOLE Meeting and at University Pompeu Fabra for useful comments. 
rium unemployment is lower and exhibits a higher turnover rate. On-thejob search renders the unemployment inflow rate more sensitive to the cycle: in all cases, the inflow rate is found to be more cyclically sensitive than the outflow rate, suggesting that most unemployment dynamics occur through this channel. This confirms empirical results for Great Britain (Burgess and Turon (2005)).

Second, our model offers some insight into a (two-way) relationship between job-to-job flows, which drives the difference between worker and job flows, and the extent of wage dispersion. More wage dispersion increases the incentive to search on-the-job and more on-the-job search widens the range of viable productivities and leads to lower wages at the bottom of the wage distribution, thereby increasing wage dispersion.

Third, changes in the model's exogenous parameters impact unemployment to a considerable degree by changing the level of employed job search.

Keywords: Unemployment, on-the-job search, worker flows, job flows, matching.

JEL classification: J64. 


\section{Introduction}

The search and matching framework has been widely used to analyse unemployment $^{1}$. A great deal of progress has been made in recent years linking the initial focus on worker flows (unemployment exits) to the newer literature on job flows (job creation and destruction) $)^{2}$. Calibrated versions of these models fit reasonably well with some labour market facts. However, there is one gross fact that conflicts with the models, and is the focus of this paper. This is the relationship between worker flows and job flows. In stark contrast to the models' predictions, job flows in fact only account for a fraction of worker flows, and unemployment exits only account for a fraction of hires. Furthermore, these fractions vary over the cycle ${ }^{3}$. These facts are key to understanding unemployment dynamics and the operation of the labour market, and need to be incorporated in the modelling process. The process driving a wedge between job and worker flows (and between unemployment exits and hires) is workers moving directly from one job to another ${ }^{4}$. In this paper, we develop and calibrate a model based on the Mortensen and Pissarides approach but that emphasises this issue. We show that this matters - that it has different implications for our view of unemployment dynamics.

\footnotetext{
${ }^{1}$ See Mortensen and Pissarides (1994) for the seminal work in this area, and Mortensen and Pissarides (1999a and 1999b) for surveys of this literature.

${ }^{2}$ Allowing for endogenous job destruction enhances the ability of the framework to assess the role of labour market frictions and the propagation of productivity shocks, see for example Merz (1999), den Haan, Ramey and Watson (2000).

${ }^{3}$ With data for Maryland, Burgess, Lane and Stevens (2000) find that only $54 \%$ of worker reallocation is accounted for by job reallocation, and that the two types of reallocation exhibit different behaviour over the business cycle. With data for several European countries, Burda and Wyplosz (1994) also found that job flows are countercyclical whereas worker flows are procyclical.

${ }^{4}$ Job-to-job flows have been documented to account for about $50 \%$ of total separations in the UK and the US and about 25\% in Italy (Contini and Revelli (1997, p.256)) and to be sensitive to the business cycle and labour market institutions (Burgess, Lane and Stevens (2000), Boeri (1999)).
} 
The key features of our model that allow us to explain the dynamics facts of the labour market relate to the search options of the worker, and the job creation decision by firms. The vast majority of this literature assumes that job search can only be undertaken by the unemployed. Notable exceptions are Mortensen (1994) and Pissarides $(2000)^{5}$. But these, along with other models, make assumptions that imply that jobs left vacant by workers quitting or retiring are destroyed. This necessarily implies that total job destruction equals total separations, and the model loses the capability to analyse them separately. Our approach allows workers to search whilst employed, and firms to re-advertise jobs that have been quit from. We produce a model of unemployment that is consistent with the stylised facts noted above. We calibrate the model and assess the response to various labour market shocks, emphasising the role of employed job search.

Our model is closest to the one by Pissarides (2000, Chapter 4). Firms are heterogenous and the value of their output is decomposed in terms of a common aggregate component and an idiosyncratic component which is subject to shocks. When the idiosyncratic productivity falls below some endogenously determined threshold, the firm destroys the job ${ }^{6}$. Workers in jobs with idiosyncratic productivity below some other endogenous threshold decide to search on-the-job. When they are successful and quit, the firm can re-advertise the vacant job at the same level of productivity and opt do to so in most cases. This is more realistic than the implication of the standard model that the job is

\footnotetext{
${ }^{5}$ Models with on-the-job search have also been developed to explain wage dispersion (Burdett and Mortensen (1998), Bontemps, Robin and van den Berg (1999), Galindo-Rueda (2002)).

${ }^{6}$ Pissarides (1994), Shimer (2003) and Eriksson and Gottfries (2002) also set up unemployment models with on-the-job search but keep job destruction exogenous.
} 
always destroyed after a quit or a retirement. This requires us to use a different job creation process, whereby potential vacancies, or job 'ideas', arise at a finite rate per period over a range of idiosyncratic productivities. In the standard setting, there is an unlimited supply of potential vacancies at the top idiosyncratic productivity and vacancies are created until the exhaustion of rents. In our setting, the marginal created vacancy makes zero profit but all other vacancies are profitable ${ }^{7}$. Vacancies are hence heterogenous. The model does not have a closed form solution, so we use a calibrated version to simulate the impact of on-the-job search on unemployment equilibrium. As Pissarides (2000), we find that more on-the-job search leads to a lower unemployment inflow rate and a slightly higher matching probability for workers. We are also able to assess the role of on-the-job search in the propagation of shocks to the economy or in relation to the role of institutions such as unemployment benefit.

The main results of the paper are as follows. First, the presence of onthe-job search has a substantial impact on labour market equilibrium, whereby equilibrium unemployment is lower and exhibits a higher turnover rate. On-thejob search renders the unemployment inflow rate more sensitive to the cycle: in all cases, the inflow rate is found to be more cyclically sensitive than the outflow rate, suggesting that most unemployment dynamics occur through this channel. This confirms empirical results for Great Britain (Burgess and Turon, 2005).

Researchers have come to see worker flows and job flows as key elements of the operation of labour markets. This model is the first in the now ubiqui-

\footnotetext{
${ }^{7}$ As opposed to vacancies in the standard model which are all posted at the maximum productivity and all make zero profit. As a result, in the standard model, there is a unique potential wage rate at the match for all job seekers, i.e. no wage distribution at the time of the match.
} 
tous matching approach to be able to analyse them separately. Other matching models either allow no employed job search and so no job-to-job flows, or make assumptions implying no worker churning - both of these routes yield the result that worker and job flows are identical. This stands in stark contrast to the facts assembled over recent years using microdata on firms, on workers and using linked firm-worker data. The facts show that worker flows and job flows are very different in magnitude, and also very different in terms of their cyclical behaviour. It is clearly important for the workhorse model of labour market analysis to be able to accommodate these facts, and this is what the model in this paper accomplishes. We suggest that the role of employed job search is potentially important in understanding the differences in labour markets between different countries. We return to this in the Conclusion.

Third, our model offers some insight into a reciprocal relationship between job-to-job flows, which drives the difference between worker and job flows, and the extent of wage dispersion. More wage dispersion increases the incentive to search on-the-job for workers in jobs at the bottom of the wage distribution. Conversely, on-the-job search renders some jobs viable at the bottom of the wage distribution that would not be so otherwise ${ }^{8}$. This is because workers who search on-the-job receive a lower wage than they would if they did not search as they share with the firm the expected surplus from their search. Some jobs with low idiosyncratic productivity are hence viable when on-the-job search is allowed, that were not so without on-the-job search. To sum up, with on-the-job search, the range of viable idiosyncratic productivities is extended downwards and firms

\footnotetext{
${ }^{8}$ The fact that employed job search supports greater wage dispersion is not a new result, but our models allows us to emphasise the reciprocal relationship between the two.
} 
with idiosyncratic productivities towards the bottom of the distribution offer lower wages because they are aware that their employees search on-the-job. So wage dispersion is increased. This in turn supports more job-to-job flows and a bigger difference between job flows and worker flows. Thus the degree of wage dispersion is linked to the nature of unemployment dynamics.

The calibrated version of our model matches empirical facts well: unemployment flows are countercyclical, job flows are countercyclical and worker flows are procyclical. It hence reconciles the different behaviours over the business cycle of job flows and worker flows.

We derive the model in the next section and present the calibration and the results in section 3. Section 4 concludes.

\section{Model}

Our model builds on the standard Mortensen-Pissarides framework ${ }^{9}$, but differs from it with respect to job search and job creation. These changes are necessary to yield a model with job-to-job flows and a distinction between job flows (job creation and job destruction) and worker flows (hires and separations). First, we incorporate on-the-job search, with an endogenous fraction of the employed finding it worthwhile to search. This is clearly necessary to allow job-to-job flows. Second, we allow for heterogeneous vacancy creation and a finite (rather than infinite) supply rate of potential new jobs per period. This is necessary to allow worker flows and job flows to be different. If all jobs that workers quit from were destroyed (as in the standard set-up), total separations would equal

\footnotetext{
${ }^{9}$ See Pissarides (2000) or Mortensen and Pissarides (1999a) for the derivation of the original model.
} 
total job destruction, so we need to allow some of those jobs to be re-advertised rather than destroyed. If all new vacancies were created at the highest idiosyncratic productivity, it would never be optimal to re-advertise an on-going job with a lower productivity. Therefore we assume heterogeneous vacancy creation. If there were an infinite supply of potential jobs ("ideas") per period, firms would reject all but the highest idiosyncratic productivity ideas and again there would be no re-advertisement. So we also assume a finite supply of potential jobs. Given these assumptions, firms find it optimal to maintain and re-advertise an endogenous fraction of jobs that workers quit from. This allows us to explore different components of the dynamics of the labour markets, for example, the different response of job flows and worker flows to shocks, the nature of unemployment dynamics and the the full consequences of on-the-job search.

As one of our aims is to set up a model of unemployment with more realistic worker flows, we also introduce flows in and out of the labour force. In Britain, the flow of entrants/re-entrants to the labour market represents half the inflow into unemployment. Garibaldi and Wasmer (2001) analyse these flows in more depth, but without considering on-the-job search ${ }^{10}$. In our model, the flows in and out of the labour force are (exogenous) constant fractions of the stock of the employed. The labour force inflow represents new entrants coming from education and re-entrants coming back after a career break. All labour force entries flow into unemployment. The labour market, through the matching mechanism, has to 'process' these workers before they find a match. The labour

\footnotetext{
${ }^{10}$ An interesting extension of both models would include endogenous on-the-job search and labour force entries and exits as both features are shown to affect unemployment dynamics.
} 
force outflow represents retirements and individuals starting a career breaks. For simplicity, all labour force exits occur from the state of employment. As documented by Burda and Wyplosz (1994) both these labour force flows occur in fact to and from both states of employment and unemployment, in cyclically sensitive proportions. Their evidence, however, supports that total labour force flows are roughly constant over the cycle.

\subsection{Workers}

We denote labour market tightness by $\theta$, and an unemployed searcher's matching probability as $\theta q(\theta)$; these are fully defined below. We assume that employed job seekers have a matching probability equal to $a$ times the matching probability of unemployed job searchers. The parameter $a$ captures the relative search effectiveness of employed job seekers and could in principle be greater or less than 1 . The per-period cost of employed job search is denoted $k$.

Once in a match, the value of the output has a common aggregate component, $p$, and an idiosyncratic component, $\epsilon$. The latter is subject to shocks arriving at rate $\lambda$ per unit time, discussed below. Following Jovanovic (1979), we assume that the job match is an experience good, so the idiosyncratic productivity is unknown to the worker at the time of the match and is only discovered once she takes the job. It is not possible for firms advertising vacant jobs with a high productivity to signal it to job seekers because they cannot commit to the promised wage once the worker is employed (because of wage renegotiation). If the idiosyncratic productivity is below an endogenous threshold $S$ the worker will find it worthwhile to continue search on the job. Because $\epsilon$ is unknown $e x$ ante, employed job seekers sample all the available vacancies, and accept all 
offers rather than just those better than their current match. Therefore, neither the matching probability $(a \theta q(\theta))$ nor the expected value of employment in the next job depend on the value of $\epsilon$ in their current job. The Bellman equations for employed workers are as follows: $E_{o}(\epsilon)$ when the worker is searching on the job, $E_{n}(\epsilon)$ when she is not:

$$
\begin{aligned}
r E_{o}(\epsilon)= & w_{o}(\epsilon)+l\left(U-E_{o}(\epsilon)\right)+a \theta q(\theta)\left[\int_{T}^{\sigma} E(x) \cdot d F_{V}(x)-E_{o}(\epsilon)\right]-(\not) \\
& +\lambda\left[\int_{R}^{\sigma} E(x) \cdot d F(x)+U \cdot F(R)-E_{o}(\epsilon)\right] \\
r E_{n}(\epsilon)= & w_{n}(\epsilon)+l\left(U-E_{n}(\epsilon)\right)+\lambda\left[\int_{R}^{\sigma} E(x) \cdot d F(x)+U \cdot F(R)-E_{o}(\epsilon\} 2\right)
\end{aligned}
$$

where $r$ is the discount rate. Taking $E_{o}(\epsilon)$, the first term on the right-hand side is the current wage, depending on idiosyncratic productivity as explained below; the second term represents retirement, and the third and fourth terms are the probability of receiving an offer multiplied by its expected value minus search cost. Jobs are created for $\epsilon$ above $T$, the endogenous job creation threshold, generating job offers. The final term reflects the impact of the evolution of the idiosyncratic term: shocks arrive at rate $\lambda$, and shocks between an endogenous threshold $R$ and $\sigma$ lead to renegotiation of the wage and so a different value of $\mathrm{E}$, while shocks pushing $\epsilon$ below $R$ lead to the job being destroyed and the worker flowing into unemployment ${ }^{11}$. The value of $E_{o}(\epsilon)$ has the same structure, obviously omitting the value and the cost of search. Note that the distribution of idiosyncratic productivities $\epsilon$ in vacant jobs, $F_{V}($.$) , is different from the distri-$ bution of $\epsilon$ following an idiosyncratic shock, $F($.). Reasons for this are detailed below and the derivation of the various density functions is given in Appendix

\footnotetext{
${ }^{11}$ Note that we assume that the time unit is such that more than one event - a job offer or an idiosyncratic shock - cannot occur at the same time.
} 
A.

The Bellman equation for unemployed workers is:

$$
r U=b+\theta q(\theta)\left(\int_{T}^{\sigma} E(x) \cdot d F_{V}(x)-U\right)
$$

where $b$ is the per-period sum of the unemployment benefit and the value of leisure, net of job search costs. With probability $\theta q(\theta)$ the unemployed receive an employment offer which they accept. We assume that the out-of-the-labourforce state value also equals $U$. The value of employment in the marginal job, $E_{o}(T)$, is greater than the value of unemployment $U$ as the surplus at $T$ is positive.

\section{$2.2 \quad$ Firms}

Potential new 'ideas' for jobs are born at a rate of $j c r$ per period and their value is distributed over the range $(-\sigma ; \sigma)$ according to a cumulative distribution function $F(\epsilon)$. The value of the output produced by firms is composed of two parts: the aggregate component, $p$ and the idiosyncratic value of the idea, $\epsilon$. When $\epsilon$ is above an endogenous threshold $T$ it is worthwhile opening a vacancy. The value of $\epsilon$ is subject to idiosyncratic shocks occurring at rate $\lambda$; the postshock distribution of $\epsilon$ is also $F(\epsilon)$. If the post-shock idiosyncratic productivity falls below an endogenous threshold $R$, the job is destroyed and the worker flows into unemployment; we show that $R<T$.

The wage is negotiated at the time of matching and is re-negotiated after either an idiosyncratic shock or an aggregate shock. The firm knows that the worker will search if the idiosyncratic productivity is below $S$, and this influences 
the wage setting process in a way described below (see section 2.3). Because of the different wage function and because of the different probability of the worker leaving the job, the value of a filled job with a non-searching worker, $J_{n}$, (that is, $\epsilon$ in the range $(S ; \sigma)$ ), is different from the value of a filled job with an on-the-job seeker, $J_{o}(\epsilon$ in the range $(T ; S))$.

The value functions for filled jobs depend on the price of output, the wage, the impact of idiosyncratic shocks and the cost of worker turnover. For values of $\epsilon$ in the interval $(T ; S)$, the firm expects the job to become vacant again with probability $a \theta q(\theta)$ (the matching probability for employed workers). It also expects the worker to leave the labour force with probability $l^{12}$. When the job becomes vacant it keeps its level of idiosyncratic productivity $\epsilon$, because this defines the job and is not attached to the worker or the worker-job match. Idiosyncratic shocks change the value of the job; shocks pushing $\epsilon$ below $R$ destroy the job (ie. $J=0)$. The Bellman equations for filled jobs, $J_{o}(\epsilon)\left(J_{n}(\epsilon)\right.$ respectively) when the worker is (respectively is not) searching on the job, are:

$$
\begin{aligned}
r J_{o}(\epsilon)= & p+\epsilon-w_{o}(\epsilon)+(l+a \theta q(\theta))\left(V_{o}(\epsilon)-J_{o}(\epsilon)\right) \\
& +\lambda\left[\int_{R}^{\sigma} J(x) \cdot d F(x)-J_{o}(\epsilon)\right] \\
r J_{n}(\epsilon)= & p+\epsilon-w_{n}(\epsilon)+l\left(V_{n}(\epsilon)-J_{n}(\epsilon)\right) \\
+ & +\lambda\left[\int_{R}^{\sigma} J(x) \cdot d F(x)-J_{n}(\epsilon)\right]
\end{aligned}
$$

The wage negotiated with a worker continuing job search, $w_{o}(\epsilon)$, will be different from the wage negotiated with a worker who stops searching, $w_{n}(\epsilon)$. Wage

\footnotetext{
${ }^{12}$ Note that in case of retirement or quit to another job, the firm plans to re-advertise the job. So separations and job destruction are different and labour force exits are not a form of exogenous job destruction: most jobs left by a retiree are re-advertised.
} 
determination is detailed in section 2.3. Whether a worker searches on the job or not does not depend on the worker herself but on the idiosyncratic productivity of the job, $\epsilon$. All workers employed in jobs with $\epsilon$ less than $S$ will be looking for another job, whilst no worker employed in a job with $\epsilon$ more than $S$ will be doing so.

The value of a vacancy will also have a different expression when $\epsilon$ is in the range $(T ; S)$, denoted $V_{o}$, from when $\epsilon$ is in the range $(S ; \sigma)$, denoted $V_{n}$. Vacant jobs have a probability $q(\theta)$ of being matched with a job searcher, determined by the matching function (see section 2.4). Since we assume that $\epsilon$ is unobserved to the worker until the match actually takes place and that no signalling can take place, all vacant jobs have the same probability of being matched, irrespective of their idiosyncratic productivity $\epsilon$. Note that the idiosyncratic value of vacant jobs is also subject to shocks. The Bellman equations for vacant jobs are:

$$
\begin{aligned}
& r V_{o}(\epsilon)=-c+q(\theta)\left(J_{o}(\epsilon)-V_{o}(\epsilon)\right)+\lambda\left[\int_{T}^{\sigma} V(x) \cdot d F(x)-V_{o}(\epsilon)\right] \\
& r V_{n}(\epsilon)=-c+q(\theta)\left(J_{n}(\epsilon)-V_{n}(\epsilon)\right)+\lambda\left[\int_{T}^{\sigma} V(x) \cdot d F(x)-V_{n}(\epsilon)\right]
\end{aligned}
$$

where $c$ is the per-period cost of opening a vacancy. As in the standard model, vacant jobs are created until rents are exhausted. What is different here is that all vacancies but the marginal one will make a positive profit ${ }^{13}$. The job creation

\footnotetext{
${ }^{13}$ In Mortensen and Pissarides (1994), all new jobs were created at the top idiosyncratic productivity - for which the profits from a vacancy is zero. Here, jobs are created over a range of idiosyncratic productivities $(T ; \sigma)$ and the profits from a vacancy are zero at $T$ and positive over the rest of the range. In den Haan, Haefke and Ramey (2001, pp. 8-10), new matches are 'accepted' by worker and firm as long as the relationship-specific productivity is greater than some threshold for which the joint surplus of the match is zero. Blanchard and Diamond $(1989$, p.9) already suggested that, in the short run, the profits from a vacancy were not necessarily zero.
} 
threshold is determined as:

$$
V_{o}(T)=0
$$

Filled jobs with idiosyncratic productivities in the range $(T ; S)$ are quit from and re-advertised at a rate $(l+a \theta q(\theta))$ whereas filled jobs with idiosyncratic productivities in the range $(S ; \sigma)$ are quit from and re-advertised at a rate $l$; filled jobs with $\epsilon$ in the range $(R ; T)$ are quit from at rate $(l+a \theta q(\theta))$ but once quit from are destroyed. Vacant jobs are all matched at the same rate, $q(\theta)$. The distribution of idiosyncratic productivity $\epsilon$ will hence be different between vacant jobs $F_{V}($.$) and filled jobs F_{E}($.$) . It is one of the model parameters. Although$ the job-to-job quit rate and the retirement rate are of similar magnitude over the whole employment stock, the retirement rate $l$ is much lower than the quit rate $a \theta q(\theta)$ for a given idiosyncratic productivities (by a factor 30 in our base calibration). This is because workers retire from the whole employment stock whereas they quit from only a small fraction of it ( $6 \%$ in our base calibration). So the distribution of $\epsilon$ in vacant jobs $F_{V}($.$) is highly concentrated in the interval$ $(T ; S)$ compared to the distribution of filled jobs $F_{E}($.$) . In our base calibration,$ about half the vacancy stock is in this range against $6 \%$ of the employment stock. The calculation of the cumulative distribution functions $F_{V}($.$) and F_{E}($. is detailed in Appendix A. The fact that the model implies these three different distributions instead of just one in the standard setting prevents us from having a simple closed form solution to our model. 


\subsection{Surplus and wage bargaining}

The wage rate is determined by Nash bargaining between worker and firm, as in the Mortensen-Pissarides framework ${ }^{14}$. However, in their framework all new matches are formed at the maximum idiosyncratic productivity, leading to a single wage rate at the match. In our setup, new matches occur over a range of idiosyncratic productivities, namely $(T ; \sigma)$. The idiosyncratic productivity of a job, $\epsilon$, is unknown to the worker at the time of the match, and is only revealed when she starts in the job. As mentioned, the wage level is renegotiated between the worker and the firm following each shock to $\epsilon$, so that it always shares the match surplus between the two parties according to their bargaining power. Before the match actually occurs, there is no wage offer apart from a knowledge of this renegotiation rule. The worker always finds it worthwhile to take up the job offer: for unemployed searchers because $E_{o}(T)$ is greater than $U$, and for employed job seekers because necessarily the expected value of alternative employment net of search costs is greater than the value of her current employment (otherwise she would not search). It may be that the employed job searcher is unlucky when she finds a new job in that she experiences a wage drop $^{15}$, but her expected returns to search were still positive ex ante.

From the equations above, we see that the surplus from a match between a vacant job and a job seeker will have a different expression for jobs in which the

\footnotetext{
${ }^{14}$ There has been a growing literature on alternative models of wage determination over the past decade, particularly models with wage-posting games (see Mortensen and Pissarides (1999b) for a survey). Here, wage dispersion is obtained with Nash bargaining wage determination.

${ }^{15}$ Nickell (2002, Table 7, p.21) reports that over $10 \%$ of job movers with no intervening spell of unemployment experience a wage drop of over $10 \%$, with data on British men over the period 1982-1996.
} 
worker carries on searching and in jobs where the worker stops searching:

$$
\begin{aligned}
& S_{o}(\epsilon)=J_{o}(\epsilon)-V_{o}(\epsilon)+E_{o}(\epsilon)-U \\
& S_{n}(\epsilon)=J_{n}(\epsilon)-V_{n}(\epsilon)+E_{n}(\epsilon)-U
\end{aligned}
$$

Because wage negotiation occurs once the worker is in the job, we assume that the worker's outside option is unemployment in both cases. As argued below, it is never optimal for a firm to attempt to retain a worker with an outside offer by making a counter-offer. The potential outside offer hence never becomes a new outside option for the worker in the wage baragining process as it would in Postel-Vinay and Robin (2002). A worker who has quit her previous job does not have the option to go back to it, hence employed and unemployed job seekers are offered the same wage rates when hired. Pissarides (1994, p.465) and Shimer (2004, p.5) make the same assumption, based on the impossibility of returning to the old employer for a worker who quits a job and on the impossibility to commit to a long-term contract to attract an employed worker for the prospective firm. So the above surplus expressions apply to matches between a vacant job and either an unemployed or an employed job seeker.

The two wage rates $w_{o}(\epsilon)$ and $w_{n}(\epsilon)$ resulting from the Nash bargaining will satisfy the following conditions:

$$
\begin{aligned}
& \beta\left(J_{o}(\epsilon)-V_{o}(\epsilon)\right)=(1-\beta)\left(E_{o}(\epsilon)-U\right) \\
& \beta\left(J_{n}(\epsilon)-V_{n}(\epsilon)\right)=(1-\beta)\left(E_{n}(\epsilon)-U\right)
\end{aligned}
$$

where $\beta$ is the worker's share of the surplus. Shimer (2004) shows that, in his model of on-the-job search, surplus sharing is not generally equivalent to the 
Nash solution. In our setting, however, because we assume $\epsilon$ to be unobserved before an offer is accepted, neither the quit rate nor the expected value of employment in the next job for employed job seekers depend on the level of their current wage. It follows that, for employed job seekers, raising $w_{o}$ by $\Delta w_{o}$ will increase the worker's side of the surplus by $[r+l+a \theta q(\theta)+\lambda] . \Delta w_{o}$ and lower the firm's side of the surplus by the same amount. The Nash solution will hence coincide with the surplus-sharing rule, in our context.

In jobs with low idiosyncratic productivity, there are expected benefits to job search for the worker as the expected value of a future job is high enough compared to the value of the current job to more than offset the search costs $k$. For the firm, employed job search represents a cost as it expects to have to re-advertise the vacancy in the near future, and the value of a vacant job is always lower than the value of the filled job for the same productivity. These two facts imply that the wage rate for workers engaged in on-the-job search, $w_{o}(\epsilon)$, is lower than the wage rate of non-searching workers, $w_{n}(\epsilon)$, over the range of productivities where workers do decide to search on-the-job, $(T ; S)$.

Firms with idiosyncratic productivities in the range $(T ; S)$ are aware that the workers they hire engage in on-the-job search. They are not tempted to stop them from doing so by offering them a higher wage because their search creates an expected benefit, that they enjoy a share of, through the Nash bargaining wage determination. In other words, as the worker expects to find a better job, the value of which more than offsets the search costs, she is better off searching. Some of this benefit from search (but not all) is taken away from her in the wage determination as she gets paid a lower wage than she would have, had she not 
searched on the job. The firm anticipates having to pay advertising costs when the worker quits, so would be worse off if the search decision did not affect the wage rate. However, because the Nash bargaining leads to a lower wage when the worker searches on the job, the firm is in fact better off if the worker does search as the wage difference more than offsets the anticipated advertising $\operatorname{costs}^{16}$. Furthermore, firms cannot afford to retain workers who have an outside offer in hand: as the new job's $\epsilon$ is unobserved until the worker actually starts in the new job, the minimum wage that the old firm would have to pay to retain the worker is a wage that matches the expected wage $E_{V}\{w\}$ that the worker anticipates. It turns out that, in all our simulations, even the firm with the highest productivity in the range where workers engage in on-the-job search $(\epsilon=S)$ cannot afford to offer such a wage, i.e. re-opening a vacancy is more profitable than retaining the worker with a wage offer of $E_{V}\{w\}$.

Firm heterogeneity, embodied in the variance of $\epsilon$, and labour market frictions, embodied by the matching function, lead to some wage dispersion ${ }^{17}$. This dispersion is an incentive for some workers paid at the lower end of the wage distribution to engage in on-the-job search. On-the-job search in turn leads to increased wage dispersion for the following two reasons. First, as these employed job seekers share the expected benefit from their search with their employer

\footnotetext{
${ }^{16}$ Shimer (2004) argues that surplus sharing may be inefficient as, in some cases, the firm is better off raising the wage in order to reduce quitting. This can occur in his model of on-thejob search where the quitting probability decreases continuously as the wage rate increases. In our context, however, the quitting probability is either 0 or $a \theta q(\theta)$. The minimum wage that the firm would have to pay to stop the worker from searching is $w_{n}(S)$. However, in the range of productivities $(R ; S)$, the firm is better off paying $w_{o}(\epsilon)$ and let the worker search on the job. So it will not attempt to discourage the worker to search.

${ }^{17}$ Following Burdett and Mortensen (1998), there are a number of models of equilibrium wage dispersion with wage-posting firms. For example, Postel-Vinay and Robin (2002) present a search model where both workers and firms are heterogenous. They estimate that worker heterogeneity contributes 0 to $40 \%$ of the wage variance, firm heterogeneity 10 to $50 \%$ and labour market frictions about $50 \%$.
} 
through the wage bargaining, they are paid less than if on-the-job search did not take place. So wages at the low end of the distribution are lower when on-the-job search occurs. Also, because firms pay lower wages, they find that more job 'ideas' are viable and the job creation and job destruction thresholds, $T$ and $R$, are lower than without on-the-job search. There is hence a two-way causal relationship between wage dispersion and on-the-job search.

\subsection{Equilibrium}

Matches between searching workers and vacant jobs occur at a rate determined by the matching function, which we assume to exhibit constant returns to scale. The pool of job searchers comprises all the unemployed job seekers, $u$,plus the employed workers engaged in on-the-job search, oj counted in terms of efficiency units $(a$ is the relative matching efficiency of employed job seekers compared to unemployed job seekers):

$$
\text { Number of matches }=\xi \cdot(u+a \cdot o j)^{(1-\alpha)} v^{\alpha}
$$

where $\xi$ is the matching efficiency, $\alpha$ the matching elasticity with respect to vacant jobs and $v$ the stock of vacancies. If we denote $\theta$ the labour market tightness:

$$
\theta=\frac{v}{u+a . o j}
$$


we have the following expressions for the workers' $(\theta q(\theta))$ and vacancies' $(q(\theta))$ matching probabilities:

$$
\begin{aligned}
\theta q(\theta) & =\xi \cdot \theta^{\alpha} \\
q(\theta) & =\xi \cdot \theta^{\alpha-1}
\end{aligned}
$$

The labour force is assumed constant and normalised to 1 , so we have the following identity between the stocks of employed $e$ and unemployed $u$ :

$$
e+u=1
$$

The equations that determine the model equilibrium are the job creation condition (18), the job destruction condition (19) and the on-the-job search threshold condition (20) as well as the flow equations for filled jobs and vacant jobs over each range of idiosyncratic productivities.

$$
\begin{aligned}
& V_{o}(T)=0 \\
& S_{o}(R)=0 \\
& S_{o}(S)=S_{n}(S)
\end{aligned}
$$

The value of $R$ is less than $T$ because the value of a filled job is positive at $T$ and the function $J_{o}($.$) is increasing. Hence, in the interval (R ; T)$, jobs survive but would not be re-advertised if the worker came to quit or retire. In this interval, workers engage in on-the-job search. $S$ is the idiosyncratic productivity at which both workers and firms are indifferent between the worker continuing or stopping search.

The derivation of the model is given in Appendix A. 


\section{Results}

We now look at a calibrated version of the model and examine the impact of on-the job search, the business cycle and various parameters on its outcome. In section 3.1 we calibrate the model to obtain a solution that mirrors reality in terms of the sizes of the various stocks and flows in the labour market in Britain. In section 3.2 we simulate the impact of the presence of on-the-job search on the unemployment rate, flows and wages. We confirm Pissarides' (2000) findings for the impact on the unemployment rate. We then turn to the main results on the dynamics: in section 3.3, we analyse cyclical sensitivities of the unemployment rate and flows by comparing different stages of the business cycle, with and without on-the-job search. Next, in section 3.4, we exploit our ability to analyse job and worker flows separately and show that the sizes and cyclical sensitivities of job flows and worker flows predicted by our model are consistent with empirical evidence. The discrepancy between job and worker flows, driven by job-to-job flows and labour force flows, is very sensitive to the cycle. The cyclical sensitivity of job-to-job flows increases the sensitivity of wage dispersion to the cycle (and is reinforced by it). Finally, the impacts of a change in unemployment benefit, and the relative matching efficiency of on-the-job are examined in section 3.5 .

\subsection{Calibration}

The targets for the calibration process are an unemployment rate of $9 \%$, an unemployment inflow rate of $4 \%$ of the labour force ${ }^{18}$, matching probabilities

\footnotetext{
${ }^{18}$ These values were chosen to match data from Great Britain (NOMIS and Burgess and Turon, 2000).
} 
of 0.40 for job seekers and 0.90 for vacant jobs. We also attempt to match the evidence (for example Burgess, 1993) that half the new hires come from the ranks of the employed and that 5 to $8 \%$ of the employed engage in job search whilst employed (Pissarides and Wadsworth, 1994), so we need to calibrate the relative matching efficiency of employed job seekers, $a$, in the range 1.1 to 1.8. We assume the distribution $F($.$) to be uniform over the range (-\sigma ; \sigma)^{19}$. The other parameters are as follows: we think of the unit time period to be a quarter and use a discount rate $r$ of 0.01 ; the bargaining parameter $\beta$ is set at 0.5 , and this sets $\alpha$ to the same value to fulfill the Hosios (1990) condition; we set $b$ at $0.8, l$ at 0.02 , matching efficiency $\xi$ at 0.6 , the arrival rate of idiosyncratic shocks, $\lambda$ at 0.15 (Mortensen and Pissarides (1994) use a value of 0.08 for $\lambda$. Our chosen value implies an expected duration of 7 quarters between shocks to the idiosyncratic productivity and, together with our calibration of the threshold $R$, gives an endogenous job destruction rate of $2 \%$ which matches British data). The values of $p$ and $\sigma$ are normalised to unity, and the cost of on-the-job search, $k$, to 0.1 . Given these values, we adjust $c, a$, and $j c r$ from plausible starting values to get close to the targets.

A summary of all parameter values for the base case is shown in Table 1.

With these parameter values we obtain a labour market tightness $\theta$ of $0.47^{20}$ and matching probabilities of 0.41 and 0.87 for workers and vacancies respectively. The resulting stocks of unemployed and employed job seekers are respectively 0.088 and 0.063 , while the stock of vacant jobs is 0.092 . The unemployment inflow rate is 0.04 . The average productivity is 1.28 , so the average

\footnotetext{
${ }^{19}$ The distributions of $\epsilon$ over vacancies and filled jobs are derived in the Appendix.

${ }^{20}$ This value of the tightness is implied by our target values for the workers' and jobs' matching probabilities.
} 
Table 1: Parameter values

\begin{tabular}{lcc}
\hline discount rate & $r$ & 0.01 \\
worker's bargaining power & $\beta$ & 0.5 \\
unemployment income & $b$ & 0.8 \\
retirement/birth rate & $l$ & 0.02 \\
advertising costs & $c$ & 0.465 \\
matching efficiency & $\xi$ & 0.6 \\
idiosyncratic shock arrival rate & $\lambda$ & 0.15 \\
matching elasticity w.r.t vacancies & $\alpha$ & 0.5 \\
(genuine) job creation rate & $j c r$ & 0.055 \\
on-the-job search costs & $k$ & 0.1 \\
aggregate component of productivity & $p$ & 1 \\
variance of idiosyncratic shock & $\sigma$ & 1 \\
employed seekers' relative efficiency & $a$ & 1.71 \\
\hline
\end{tabular}

replacement ratio $(b / w)$ is $63 \%$. The value of $a$ chosen for our base case, 1.71 , is broadly consistent with findings by Blau and Robins (1990): with data from the United States, they find that employed job seekers enjoy on average 0.30 job offers per week, whereas the figure for unemployed job seekers is only 0.18. Eriksson and Gottfries (2002) perform some simulations of their model and obtain values of $a$ of 1.7 for the US and 4 for France and Germany.

\subsection{Impact of on-the-job search}

We get at the role of on-the-job search in two ways. First, we look at marginal changes by varying the cost of on-the-job search, $k$. Second, we simulate the model with no on-the-job search (with a setting similar to the above, but where on-the-job search is not allowed. This model is briefly derived in Appendix B). We focus on the impact on unemployment flows, the unemployment rate, and wage dispersion. Results are reported in Table 2.

We see that the stock of employed job seekers, $o j$, responds negatively to a change in $k$. The elasticity of this stock to the search cost $k$ is -0.51 . The 
Table 2: Impact of on-the-job search

\begin{tabular}{lccc}
\hline & & Base & $k=0.15$ \\
\hline \hline labour market tightness & $\theta$ & 0.47 & 0.43 \\
u. workers' matching probability & $\theta q(\theta)$ & 0.41 & 0.40 \\
unemployed job seekers & $u$ & 0.088 & 0.099 \\
employed job seekers & $o j$ & 0.063 & 0.047 \\
vacancies & $v$ & 0.092 & 0.078 \\
unemployment inflow & $U i$ & 0.040 & 0.043 \\
average productivity (filled jobs) & avge & 1.28 & 1.28 \\
ratio highest to lowest wage & $w_{\max } / w_{\min }$ & 1.81 & 1.66 \\
std dev of wages (filled jobs) & & 0.094 & 0.080 \\
\hline
\end{tabular}

A rise in $k$ reduces employed job search

expected surplus from on-the-job search is lower when we increase job search costs $(k)$, so the wage paid to these employed job seekers is higher than when $k$ was low (in the base case). As a consequence the job destruction threshold rises, leading to an increase of the unemployment inflow rate. The elasticity of the unemployment inflow rate to employed job search costs is 0.15 . The decrease in the number of employed job seekers has a small and negative impact on $\theta q(\theta)$ - the elasticity of the unemployment outflow rate to employed job search costs equals 0.05 , three times smaller than the elasticity of the unemployment inflow rate to $k$. Employed job seekers generate more vacancies in the market, firstly because most jobs quit from are re-advertised, secondly because, their presence lowers the job creation threshold, as detailed above. They also create competition for the unemployed for vacancies. The former effect is slightly stronger, so overall there is a negative impact of less employed job search on the unemployed searchers' chances to find a job. The impact of less on-the job search on the unemployment inflow and outflow rates both lead to a higher unemployment rate. The size of unemployment flows, or unemployment turnover 
$(U F=U i .(1-u)=\theta q(\theta) u)$ is higher when there is less on-the job $(U F=0.036$ in the base case and $U F=0.040$ when $k=0.15)$ although the outflow rate is (slightly) lower.

This differs from the results of Boeri (1999), who observes that countries with a high fraction of employed job search exhibit lower unemployment turnover rates. Pissarides (2000), however, finds no congestion effect from increased on-the-job search. In his model, lower search costs for the employed leads to more employed job search and more job creation. The net effect on tightness is positive (i.e. a less congested labour market on the workers' side) as in our framework. In his model, job destruction decreases too, so the overall effect on unemployment is a decrease as in our setting. In both models, a decrease in the search costs for the employed leads to an ambiguous shift of the Beveridge curve (see results in Table ??). Fuentes (2002) finds empirically that more onthe-job search shifts the Beveridge curve out, with data on British regions over the period 1979-1993.

Another consequence of increased on-the-job search is an increase in wage dispersion. More on-the-job search leads to a lower job creation threshold, so a wider range of viable idiosyncratic productivities ${ }^{21}$. Also, the wage rate paid to employed job seekers is lower than the wage paid to employed workers who do not engage in search, so this combines with the previous effect to increase wage dispersion. With no on-the-job search, the wage rate attached to the highest viable idiosyncratic productivity is $22 \%$ higher than the wage attached

\footnotetext{
${ }^{21}$ The average productivity is not affected however (see last line of the table) because, although more job survive when on-the-job search is allowed ( $R$ is lower), the density of the distribution of $\epsilon$ in filled jobs is lower on the interval $(T ; S)$ than on the interval $(S ; \sigma)$ as jobs are quit at a higher rate on the former interval than on the latter.
} 
to the lowest viable productivity. When on-the-job search is allowed (as in our base case), the highest wage rate is $81 \%$ above the lowest wage. The standard deviation of wages increases from 0.055 to 0.094 when we allow on-the-job search compared to when we do not. When employed job search is decreased through higher search costs ( $k=0.15$ column), the ratio of maximum to minimum wage drops to 1.66 and the standard deviation of wages to 0.08 . This result supports a recent literature that regards on-the job search as an important source of wage dispersion (Burdett and Mortensen (1998), Bontemps, Robin and van den Berg (1999), Dolado, Jansen and Jimeno, 2003).We argue (see above, section 2.3) that the extent of ojs and the degree of wage dispersion are in fact mutually reinforcing.

\subsection{Employed job search and the Transmission of Business Cycle shifts}

This section shows how shifts in the business cycle are transmitted to labour outcomes in our model. These results highlight the crucial role of on-the-job search in the cyclical dynamics of the labour market. The sensitivity of both unemployment flow rates, the unemployment rate, and the wage dispersion to the state of the business cylce is greatly affected by the presence of on-the-job search and its own sensitivity to the cycle.

We look at the impact of a change in the aggregate price component $p$ by comparing steady-states for different values of $p$, embodying once-and-for-all unanticipated shocks to the aggregate activity ${ }^{22}$. Results are shown Table 3.

\footnotetext{
22 This comparative statics exercise is less informative than a dynamic simulation of a stochastic version of the model, as in Pissarides (2000) or Shimer (2003a, p.14), but the greater complexity of our model means that this is not feasible.
} 
Table 3: Impact of business cycle and on-the-job search

\begin{tabular}{lccccc}
\hline & & Base & $p=1.1$ & $\begin{array}{c}p=1 \\
\text { no OJS }\end{array}$ & $\begin{array}{c}p=1.1 \\
\text { no OJS }\end{array}$ \\
\hline \hline Lab. market tightness & $\theta$ & 0.47 & 0.68 & 0.36 & 0.50 \\
U. outflow rate & $\theta q(\theta)$ & 0.41 & 0.50 & 0.36 & 0.43 \\
Unemployed job seekers & $u$ & 0.088 & 0.050 & 0.147 & 0.124 \\
Employed job seekers & $o j$ & 0.063 & 0.070 & 0 & 0 \\
Vacancies & $v$ & 0.092 & 0.116 & 0.052 & 0.062 \\
U. inflow rate & $U i$ & 0.040 & 0.026 & 0.062 & 0.060 \\
Avge prod. (filled jobs) & avge & 1.281 & 1.370 & 1.287 & 1.379 \\
Rto highest to lowest wage & $w_{\max } / w_{\min }$ & 1.81 & 2.27 & 1.22 & 1.23 \\
Std dev wages (filled jobs) & & 0.094 & 0.130 & 0.055 & 0.063 \\
\hline
\end{tabular}

A higher value of $p$ simulates a boom.

First, note that labour market tightness $\theta$, the workers' matching probability $\theta q(\theta)$, and the stock of vacancies $v$ are procyclical while the vacancies' matching probability $q(\theta)$, the stock of unemployment $u$ and the unemployment inflow rate $L a$ are countercyclical. This confirms the model's congruence with basic labour market facts. The stock of employed job searchers is pro-cyclical with a concave relationship between $p$ and $o j^{23}$. The quit rate, as the product of $o j$ and the matching probability $\theta q(\theta)$ (and $a$ ) will be super-procyclical, as observed in $\operatorname{data}^{24}$.

We are interested in how the presence of employed job search influences the nature of unemployment. The last two columns of Table ?? show the results when there is no employed job search. Comparing these with results with employed job search shows how employed job search affects the cyclical sensitivity of unemployment flow rates. With no employed job search the elasticity of the unemployment inflow rate with respect to $p$ is -0.3 (instead of -3.4 with em-

\footnotetext{
${ }^{23}$ The concavity of this relationship is observed when running simulations for several values of $p$ (results unreported here).

${ }^{24}$ See for example, Burgess, Lane and Stevens (2000) or Boeri (1999).
} 
ployed job search) and the elasticity of the workers' matching probability $\theta q(\theta)$ with respect to $p$ is 2.1 (instead of 2.3 with employed job search). So we see that the presence of employed job search renders the unemployment inflow rate more sensitive to the cycle, but it does not substantially affect the cyclical sensitivity of the outflow rate. The intuition for this in our model is that changes in the inflow rate are accentuated by the response of employed job search to the cycle, which in turn has a substantial effect on the inflow rate reinforcing the cyclical effect. As we saw in section 3.2, on-the-job search does not affect the unemployment outflow rate much (but also in the same direction as the cycle), which explains the small difference in the outflow cyclical sensitivity between the two models.

With employed job search, business cycle shocks will appear disproportionately as shocks to the inflow rate. This fits well with the results of Burgess and Turon (2005) for Britain. The implication of this is that unemployment dynamics, and in particular the nature of the transmission of business cycle shocks to unemployment, depends on on-the-job search. For example, international differences in unemployment dynamics (see for example Balmaseda, Dolado and Lopez-Salido, 2000, or Balakrishnan and Michelacci, 2001) may arise from differences in on-the-job search, as well as other (institutional) differences.

The stock of vacancies $v$ is procyclical and has an elasticity of 3.1 with respect to $p$, while the stock of unemployment $u$ is countercyclical and exhibits an elasticity of -5.5 with respect to $p$. With no employed job search these numbers are 2.1 and -2.0 respectively. This yields the well-known negative correlation between unemployment and vacancies over the business cycle - the 
Beveridge curve. Note that with employed job search, the U/V ratio is far more cyclically sensitive than in the standard set-up with this. This relates closely to Shimer's (2005) critique of standard search and matching models - an issue we pursue in another paper.

With employed job search, we also observe that the stock of vacancies is more cyclically sensitive than the unemployment outflow rate $\theta q(\theta)$ (the respective elasticities are 3.1 and 2.3). This is explained by the fact that, when there are more vacancies around, more employed workers engage in job search attracted by these increased opportunities and they crowd out unemployed workers although their presence has a net positive impact on the unemployed matching rate. The increase in matching probability for the workers is hence less than it would have been without employed job search. The creation of new vacancies to be posted when they quit their jobs more than offsets the crowding out to yield a slightly pro-cyclical outflow rate.

Wage dispersion increases in booms and, as we saw in the previous section, with on-the-job search. With employed job search, its cyclical sensitivity is much higher than without employed job search (respective elasticities of the standard deviation of wages with respect to $p$ are 3.8 and 1.5), because of the response of the number of employed job seekers to changes in $p$.

\subsection{Job flows and worker flows}

One of the key points of our model, and unlike other search and matching models, is that job flows and worker flows do not coincide. Not all the jobs destroyed incur layoffs because some workers either leave the labour force or take another job. Job creation and unemployment outflows do not coincide as 
some new jobs (about half of them) are taken by employed job searchers. Jobto-job moves give rise to new vacancies and new hires, but without job creation when the firm decides to replace those workers who quit. Unemployment inflows include not only layoffs but also entries into the labour force. We present in Table 4 some measures of job flows and worker flows in the base case $(p=1)$, in a recession $(p=0.9)$ and in a boom $(p=1.1)$.

We define the various job and worker flows in the following way:

$$
\begin{aligned}
\text { Job flows: } & J F=\lambda \cdot F(R) \cdot e \\
\text { Job-to-job flows: } & J J F=a \theta q(\theta) \cdot o j \\
\text { Unemployment flows: } & U F=(\lambda \cdot F(R)+l) \cdot e=\theta q(\theta) \cdot u \\
\text { Labour force flows: } & L F=l \cdot e \\
\text { Worker flows } \quad: & W F=U F+J J F=J F+L F+J J F
\end{aligned}
$$

Table 4: Job flows and worker flows

\begin{tabular}{lcc}
\hline & $p=1$ & $p=1.1$ \\
\hline \hline Job flows & 0.018 & 0.006 \\
U flows & 0.036 & 0.025 \\
L flows & 0.018 & 0.019 \\
JJ flows & 0.044 & 0.060 \\
Worker flows & 0.080 & 0.085 \\
$\mathrm{JF} / \mathrm{WF}$ & 0.23 & 0.07 \\
$\mathrm{UF} / \mathrm{JF}$ & 2.00 & 4.17 \\
\hline A higher value of $p$ simulates a boom.
\end{tabular}

Table 4 shows that our model produces countercyclical unemployment flows, consistent with the data presented by Burda and Wyplosz (1994) for four European countries. Job flows are also countercyclical ${ }^{25}$, whereas worker flows

\footnotetext{
${ }^{25}$ Many studies have found evidence of countercyclical job flows (see for example Davis and Haltiwanger (1992) or Burgess, Lane and Stevens (2000)). Boeri (1996) however questions
} 
are procyclical. The ratios between these flows show that unemployment flows, worker flows and job flows have very different cyclical behaviour. As noted, job destruction does not coincide with separations, i.e. worker flows. Indeed, the ratio between the two not only is much smaller than 1 , but is very sensitive to the business cycle. We argue that standard search and matching models which cannot distinguish job and worker flows miss a significant aspect of labour market dynamics.

Our understanding of the difference between worker flows and job flows, driven by job-to-job flows and labour force flows, seems to us important in the analysis of unemployment dynamics as it affects both the level and the cyclical behaviour of the unemployment rate and flows. Researchers have come to see worker flows and job flows as key elements of the operation of labour markets. This model is the first in the now ubiquitous matching approach to be able to analyse them separately.

Contini and Revelli (1997, Table 6, p. 258) report gross worker turnover figures to be between 2.5 to 3.9 larger than job turnover figures for France, Germany, the US, Canada and Italy. Lane, Stevens and Burgess (1996) find that worker reallocation is two to three times greater than job reallocation with data for Maryland. Our model predicts the ratio of worker to job flows to vary between 5.5 and 17 over the cycle.

\subsection{Impact of search parameters}

In this section, we turn to consider the impact of two model parameters of interest in this environment: the level of unemployment benefit $b$, is relevant this finding. 
to policy analysis, and the ranking parameter, $a$, influences the competition between employed and unemployed searchers. Results are shown in Table 5 for the base case, for an $13 \%$ increase in the unemployment income, to 0.9 , and for a $17 \%$ increase in the relative efficiency of employed job seekers, to 2 .

Table 5: Impact of unemployment benefit, worker's share and variance of idiosyncratic productivity

\begin{tabular}{lcccc}
\hline & & Base & $b=0.9$ & $a=2$ \\
\hline \hline market tightness & $\theta$ & 0.47 & 0.26 & 0.49 \\
U outflow rate & $\theta q(\theta)$ & 0.41 & 0.31 & 0.42 \\
unemployed job seekers & $u$ & 0.088 & 0.147 & 0.076 \\
employed job seekers & $o j$ & 0.063 & 0.045 & 0.064 \\
vacancies & $v$ & 0.092 & 0.059 & 0.101 \\
U inflow rate & $U i$ & 0.040 & 0.053 & 0.035 \\
avge prod. (filled jobs) & avge & 1.281 & 1.295 & 1.280 \\
rto highest to lowest wage & $w_{\max } / w_{\min }$ & 1.81 & 1.385 & \\
\hline std dev wages (filled jobs) & & 0.094 & 0.059 & \\
\hline
\end{tabular}

Base has $b=0.8$, and $a=1.71$

An increase in the unemployment income $b$ leads to an increase in $u$ and a decrease in $\theta q(\theta)$ as predicted by unemployed job search theory. In this model, an increase in $b$ also has a large impact on the job destruction rate. In the wage bargaining, the workers' outside option, $U$, is worth more when $b$ is higher, so the negotiated wage rate will be higher. The consequence is that some jobs with low idiosyncratic productivity $\epsilon$ will no longer be profitable. In other words, the job creation threshold $T$ will be higher and less vacancies will be advertised. For the same reason, the job destruction threshold $R$ will be higher, so the probability that the idiosyncratic productivity falls below that threshold after a shock will be higher, hence the higher job destruction rate. A consequence of this is that the average productivity is positively correlated 
with unemployment benefit, as in den Haan, Haefke and Ramey (2001, p.21). We also find that an increase in unemployment benefit reduces wage inequality. When $b$ equals 0.9 , the maximum wage exceeds the minimum wage by only $39 \%$ (and the wage standard deviation in filled jobs is 0.06 ), as opposed to $81 \%$ (and the wage standard deviation in filled jobs is 0.09 ), when $b$ equals 0.8 . These are sizeable effects. The intuition is that wages over the range $(R ; S)$ of the distribution, where on-the-job search occurs, are raised much more (by about 0.09 in our simulation) than wages over the range $(S ; T)$, where no on-the-job search occurs, (virtually unchanged in our simulation). A sketch explanation for this differential is provided in Appendix C.

The results also show that the impact of an increase in unemployment benefit is greater on the unemployment inflow (with an elasticity of -2.6) than on the outflow rate (with an elasticity of -2.0). Part of this equilibrium outcome works through lower employed job search: as the matching probability is lower and the variance of job opportunities is lower, employed job search is much less attractive: the elasticity of $o j$ with respect to $b$ is -2.3 .

There is a large literature on the impact of unemployment benefit on unemployment. Layard, Nickell and Jackman (1991) review this literature and report a range of estimates for the elasticity of unemployment duration with respect to unemployment duration of 0.2 to 0.9 . Our results yield a higher elasticity of 2.0. Our model, however, predicts a general equilibrium effect of unemployment benefit on unemployment. With cross-country data for the OECD, Layard, Nickell and Jackman (1991) find an elasticity of unemployment with respect to unemployment insurance replacement ratio of around one. With our calibrated value 
of $b$, the average replacement ratio over filled jobs in the base case is $75 \%$. The elasticity of the unemployment stock with respect to replacement ratio predicted by our model is 6.0. Costain and Reiter (2003) argue that standard job matching models cannot be calibrated so as to match both the long-run response of unemployment to unemployment benefit and the business-cycle frequency volatility of unemployment. They show that introducing embodied technological change or sticky wages improve the model's ability to match both types of stylised facts.

An increase in the parameter $a$, which represents an increase in the extent of ranking between employed and unemployed job seekers, leads to lower unemployment and a virtually identical unemployment turnover rate. This seems counter-intuitive and is worth spending some time on. A higher value of $a$ encourages more employed job search, and so leads to a higher quit rate and hence more vacancies. It also leads to a lower job destruction threshold and hence lower unemployment inflow rate. In this sense it functions like a fall in the cost of employed job search, which as noted above, reduces unemployment. This effect cancels out the obvious direct impact on the chances of unemployed searchers from a greater disproportionate chance for employed searchers, so that the outflow rate is unchanged. The lower unemployment inflow rate reduces unemployment.

Kugler and Saint Paul (2003) and Eriksson and Gottfries (2002) find that more ranking leads to a higher and more stagnant unemployment. However, these models are very different to the one set out here - Kugler and Saint Paul's model is based on adverse selection whereas we have identical workers, and Eriksson and Gottfries is not a matching model. 


\section{Conclusion}

This paper uses the search and matching framework to explore the role of employed job search in the labour market. With our model, we can analyse its impact in terms of unemployment level and dynamics, job creation and job destruction, hires and separations. The specific features of the model are endogenous employed job search, flows in and out of the labour force, endogenous job destruction and heterogeneous job creation. In our model, job flows and workers flows do not coincide as we allow for job-to-job flows, firms' churning of workers and labour force entries and exits. Employed job search has a substantial impact on unemployment dynamics. More on-the-job search leads to a lower unemployment inflow rate and a marginally higher outflow rate. The sensitivity of the labour market to the business cycle is affected too: with employed job search, the stock of vacancies is more cyclically sensitive and the unemployment inflow rate more cyclically sensitive than without employed job search. The cyclical sensitivity of the unemployment outflow rate is not substantially affected. One consequence is that most unemployment dynamics arise through the inflow response to cyclical shocks.

Researchers have come to see worker flows and job flows as key elements of the operation of labour markets. This model is the first in the now ubiquitous matching approach to be able to analyse them separately. Other matching models either allow no employed job search and so no job-to-job flows, or make assumptions implying no worker churning - both of these routes yield the result that worker and job flows are identical. This stands in stark contrast to 
the facts assembled over recent years using microdata on firms, on workers and using linked firm-worker data. The facts show that worker flows and job flows are very different in magnitude, and also very different in terms of their cyclical behaviour. It is clearly important for the workhorse model of labour market analysis to be able to accommodate these facts, and this is what the model in this paper accomplishes. We suggest that the role of employed job search is potentially important in understanding the differences in labour markets between different countries. For example, an economy where employed job search was cheap and easy would show experience a low unemployment rate, high wage dispersion, high worker flows, and a high ratio of worker to job flows. Conversely, an economy with costly employed job search would see higher unemployment, lower wage dispersion and lower worker flow rates. Arguably these are reasonable caricatures of the US and Europe; whilst clearly other factors are also involved, our analysis suggests there may be a role for employed job search in understanding these differences. 


\section{Appendix A}

The expression of the surplus is different over the three ranges of values of $\epsilon$. Over the interval $(R ; T)$, the value of a vacancy is zero. We have (adding up (4) (1) and (3), and substituting $E-U$ by $\beta S$ from (11)):

$$
\begin{aligned}
{[l+r+a \theta q(\theta)+\lambda] S_{o}(\epsilon)=} & p+\epsilon-b-k+\theta q(\theta)(a-1) \beta \int_{T}^{\sigma} S(x) d F_{V}(x) \\
& +\lambda \int_{R}^{\sigma} S(x) d F(x)+\lambda \int_{R}^{\sigma} V(x) d F(x) \quad \text { (A.1) }
\end{aligned}
$$

hence

$$
S_{o}^{\prime}(\epsilon)=\frac{1}{l+r+a \theta q(\theta)+\lambda}=\frac{1}{\zeta_{1}}
$$

where $\zeta_{1}=l+r+a \theta q(\theta)+\lambda$.

Over $(T ; S)$, vacancies are viable and are determined by $(6)$. So the expression of the surplus becomes (substituting $J-V$ by $(1-\beta) S$ from (11)):

$$
\begin{aligned}
{[l+r+a \theta q(\theta)+\lambda+q(\theta)(1-\beta)] S_{o}(\epsilon)=} & p+\epsilon+c-b-k \\
& +\theta q(\theta)(a-1) \beta \int_{T}^{\sigma} S(x) d F_{V}(x) \\
& +\lambda \int_{R}^{\sigma} S(x) d F(x)
\end{aligned}
$$

hence

$$
S_{o}^{\prime}(\epsilon)=\frac{1}{l+r+a \theta q(\theta)+\lambda+q(\theta)(1-\beta)}=\frac{1}{\zeta_{2}}
$$

where $\zeta_{2}=l+r+a \theta q(\theta)+\lambda+q(\theta)(1-\beta)$.

Over $(S ; \sigma)$, we use $(7),(5),(2)$ and $(3)$ :

$$
\begin{aligned}
(l+r+a \theta q(\theta)+\lambda+q(\theta)(1-\beta)) . S_{n}(\epsilon)= & p+\epsilon+c-b \\
& -\theta q(\theta) \beta \int_{T}^{\sigma} S(x) d F_{V}(x) \\
& +\lambda \int_{R}^{\sigma} S(x) d F(x)
\end{aligned}
$$

hence

$$
S_{n}^{\prime}(\epsilon)=\frac{1}{l+r+\lambda+q(\theta)(1-\beta)}=\frac{1}{\zeta_{3}}
$$

where $\zeta_{3}=l+r+\lambda+q(\theta)(1-\beta)$.

We need an expression for $\int_{R}^{\sigma} V(x) d F(x)$. From (6) and (7), we have for $i=o, n$ :

$$
\lambda \int_{T}^{\sigma} V(x) d F(x)=(r+\lambda) V_{i}(\epsilon)+c-q(\theta)(1-\beta) S_{i}(\epsilon)
$$


Integrating over $(T ; \sigma)$ and solving for $\int_{R}^{\sigma} V(x) d F(x)$ :

$$
\int_{R}^{\sigma} V(x) d F(x)=\frac{1}{r+\lambda F(T)}\left[-c \bar{F}(T)+q(\theta)(1-\beta) \int_{T}^{\sigma} S(x) d F(x)\right]
$$

where $\bar{F}=1-F$. Also, integrating by parts, we have:

$$
\begin{aligned}
\int_{T}^{\sigma} S(x) d F(x)= & S_{o}(T) \bar{F}(T)+\frac{1}{\zeta_{2}} \int_{T}^{S} \bar{F}(x) d x \\
& +\frac{1}{\zeta_{3}} \int_{S}^{\sigma} \bar{F}(x) d x \\
\int_{T}^{\sigma} S(x) d F_{V}(x)= & S_{o}(T)+\frac{1}{\zeta_{2}} \int_{T}^{S} \overline{F_{V}}(x) d x \\
& +\frac{1}{\zeta_{3}} \int_{S}^{\sigma} \overline{F_{V}}(x) d x \\
\int_{R}^{\sigma} S(x) d F(x)= & \frac{1}{\zeta_{1}} \int_{R}^{T} \bar{F}(x) d x+\frac{1}{\zeta_{2}} \int_{T}^{S} \bar{F}(x) d x \\
& +\frac{1}{\zeta_{3}} \int_{S}^{\sigma} \bar{F}(x) d x
\end{aligned}
$$

where $\overline{F_{V}}=1-F_{V}$. From (19) and (A.2):

$$
S_{o}(T)=\frac{T-R}{\zeta_{1}}
$$

Using this, (6), (A.8) and (A.9), the job creation condition (18) becomes:

$$
\frac{T-R}{\zeta_{1}}=\frac{c}{q(\theta)(1-\beta)}-\frac{\lambda}{\lambda+r}\left[\frac{1}{\zeta_{2}} \int_{T}^{S} \bar{F}(x) d x+\frac{1}{\zeta_{3}} \int_{S}^{\sigma} \bar{F}(x) d x\right]
$$

Using (A.1), (A.8), (A.12) and (A.11), the job destruction condition (19) becomes:

$$
\begin{aligned}
{[q(\theta)(1-\beta)-\theta q(\theta)(a-1) \beta] \frac{T-R}{\zeta_{1}}=} & p+R-b-k+c \\
& +\theta q(\theta)(a-1) \beta\left[\frac{1}{\zeta_{2}} \int_{T}^{S} \overline{F_{V}}(x) d x+\frac{1}{\zeta_{3}} \int_{S}^{\sigma} \overline{F_{V}}(x) d x\right] \\
& +\lambda\left[\frac{1}{\zeta_{1}} \int_{R}^{T} \bar{F}(x) d x+\frac{1}{\zeta_{2}} \int_{T}^{S} \bar{F}(x) d x+\frac{1}{\zeta_{3}} \int_{S}^{\sigma} \bar{F}(x) d x\right]
\end{aligned}
$$

From (A.12) and (A.4):

$$
S_{o}(S)=\frac{T-R}{\zeta_{1}}+\frac{S-T}{\zeta_{2}}
$$


Using this and (A.9) to (A.11), the condition for the on-the-job search threshold (20) becomes:

$a \theta q(\theta) \cdot \frac{S-T}{\zeta_{2}}=-k-a \theta q(\theta) \cdot \frac{T-R}{\zeta_{1}}(1-\beta)+a \theta q(\theta) \beta\left[\frac{1}{\zeta_{2}} \int_{T}^{S} \overline{F_{V}}(x) d x+\frac{1}{\zeta_{3}} \int_{S}^{\sigma} \overline{F_{V}}(x) d x\right]$

Equations (A.13), (A.14) and (A.16) give us the thresholds $R, T$ and $S$ as functions of the tightness and the density functions $F$ and $F_{V}$. We consider $F$ as the exogenous distribution of idiosyncratic productivities of new potential 'job ideas' and of idiosyncratic productivities after shocks. $F_{V}$ (respectively $F_{E}$ ) is the distribution of $\epsilon$ over vacant (respectively filled) jobs. These two distributions are endogenously determined by the model. In steady-state, the equality between flows in and out of filled jobs over the different ranges of idiosyncratic productivities has the following expressions:

Over $(R ; T)$ :

$$
F_{E}(\epsilon)=\frac{\lambda}{l+a \theta q(\theta)+\lambda}(F(\epsilon)-F(R))
$$

Over $(T ; S)$ :

$$
F_{V}(\epsilon)=\frac{1-u}{q(\theta) v}\left[(l+a \theta q(\theta)+\lambda)\left(F_{E}(\epsilon)-F_{E}(T)\right)-\lambda(F(\epsilon)-F(T))\right]
$$

Over $(S ; \sigma)$ :

$$
1-F_{V}(\epsilon)=\frac{1-u}{q(\theta) v}\left[l+\lambda F(\epsilon)-F_{E}(\epsilon)(l+\lambda)\right]
$$

The equality between flows in and out of vacant jobs over the different ranges of idiosyncratic productivities has the following expressions:

Over $(T ; S)$ :

$$
F_{V}(\epsilon)=\frac{1}{(q(\theta)+\lambda) v}\left[(l+a \theta q(\theta))\left(F_{E}(\epsilon)-F_{E}(T)\right) e+(j c r+\lambda \cdot v)(F(\epsilon)-F(T))\right]
$$

Over $(S ; \sigma)$ :

$$
1-F_{V}(\epsilon)=\frac{1}{(q(\theta)+\lambda) v}\left[l\left(1-F_{E}(\epsilon)\right) e+(j c r+\lambda . v)(1-F(\epsilon))\right]
$$

Taking (A.17) at $\epsilon=T$ :

$$
F_{E}(T)=\frac{\lambda}{l+a \theta q(\theta)+\lambda}(F(T)-F(R))
$$


Taking (A.18) and (A.19) at $\epsilon=S$ :

$$
\begin{aligned}
F_{V}(S) & =\frac{1-u}{q(\theta) v}\left[\begin{array}{c}
(l+a \theta q(\theta)+\lambda)\left(F_{E}(S)-F_{E}(T)\right) \\
-\lambda(F(S)-F(T))
\end{array}\right] \\
1-F_{V}(S) & =\frac{1-u}{q(\theta) v}\left[l+\lambda F(S)-F_{E}(S)(l+\lambda)\right]
\end{aligned}
$$

Taking (A.20) and (A.21) at $\epsilon=S$ :

$$
\begin{aligned}
F_{V}(S) & =\frac{1}{(q(\theta)+\lambda) v}\left[\begin{array}{c}
(l+a \theta q(\theta))\left(F_{E}(S)-F_{E}(T)\right) e \\
+(j c r+\lambda . v)(F(S)-F(T))
\end{array}\right] \\
1-F_{V}(S) & =\frac{1}{(q(\theta)+\lambda) v}\left[\begin{array}{c}
l\left(1-F_{E}(S)\right) e \\
+(j c r+\lambda . v)(1-F(S))
\end{array}\right]
\end{aligned}
$$

Rearranging (A.22) to (A.26) and using (17), we solve for $F_{E}(T), F_{E}(S)$, $F_{V}(S)$, uand $v$ (the equations are shown here only partially solved for the sake of space):

$$
\begin{aligned}
F_{E}(T) & =\frac{\lambda}{l+a \theta q(\theta)+\lambda}(F(T)-F(R)) \\
F_{V}(S) & =\frac{1-u}{q(\theta) v}\left[\begin{array}{c}
(l+a \theta q(\theta)+\lambda)\left(F_{E}(S)-F_{E}(T)\right) \\
-\lambda(F(S)-F(T))
\end{array}\right] \\
F_{V}(S) & =\frac{1}{(q(\theta)+\lambda) v}\left[\begin{array}{c}
(l+a \theta q(\theta))\left(F_{E}(S)-F_{E}(T)\right)(1-u) \\
+(j c r+\lambda . v)(F(S)-F(T))
\end{array}\right] \\
u & =\frac{l+\lambda F(R)}{\theta q(\theta)+l+\lambda F(R)} \\
v & =\frac{1}{q(\theta)+\lambda}\left[\begin{array}{c}
\left.\left(l+a \theta q(\theta) F_{E}(S)-F_{E}(T)(l+a \theta q(\theta))\right)\left(1-\mu_{2}\right) .31\right) \\
+(j c r+\lambda . v)(1-F(T))
\end{array}\right.
\end{aligned}
$$

The stock of employed job seekers is given by:

$$
o j=F_{E}(S)(1-u)
$$

The labour market tightness (and hence $\theta q(\theta)$ and $q(\theta)$ ) is then obtained with (14). The distribution function $F_{V}($.$) is then given by (A.20) and (A.21) and$ allows us to solve the three conditions (A.13), (A.14) and (A.16). 


\section{Appendix B}

We briefly derive here the model without on-the-job search.

The job creation condition becomes:

$$
\begin{aligned}
\frac{T-R}{\zeta_{1}^{n}} & =\frac{c}{q(\theta)(1-\beta)}-\frac{\lambda}{\lambda+r} \cdot \frac{1}{\zeta_{3}^{n}} \int_{T}^{\sigma} \bar{F}(x) d x \\
\zeta_{3}^{n} & =l+r+\lambda+q(\theta)(1-\beta) \\
\zeta_{3}^{n} & =l+r+\lambda
\end{aligned}
$$

and the job destruction is now:

$$
\begin{aligned}
{\left[\zeta_{3}^{n}+\beta \theta q(\theta)\right] \frac{T-R}{\zeta_{1}^{n}}=} & p+T-b+c \\
& -\theta q(\theta) \beta\left[\frac{1}{\zeta_{3}^{n}} \int_{T}^{\sigma} \overline{F_{V}}(x) d x\right] \\
& +\lambda\left[\frac{1}{\zeta_{1}^{n}} \int_{R}^{T} \bar{F}(x) d x+\frac{1}{\zeta_{3}^{n}} \int_{T}^{\sigma} \bar{F}(x) d x\right]
\end{aligned}
$$

The equality between flows in and out of vacant jobs and filled over the different ranges of idiosyncratic productivities now have the following expressions:

Over $(R ; T)$ :

$$
F_{E}(\epsilon)=\frac{\lambda}{l+\lambda}(F(\epsilon)-F(R))
$$

$\operatorname{Over}(T ; \sigma)$ :

$$
\begin{aligned}
& F_{V}(\epsilon)=\frac{1-u}{\theta q(\theta) u}\left[(l+\lambda) F_{E}(\epsilon)-\lambda(F(\epsilon)-F(R))\right] \\
& F_{V}(\epsilon)=\frac{1}{(q(\theta)+\lambda) v}\left[l\left(F_{E}(\epsilon)-F_{E}(T)\right) \cdot e+(j c r+\lambda . v)(F(\epsilon)-F(\text { (Т) })] \cdot\right)
\end{aligned}
$$

The equilibrium stocks of unemployment and vacancies are then:

$$
\begin{aligned}
u & =\frac{l+\lambda F(R)}{\theta q(\theta)+l+\lambda F(R)} \\
v & =\frac{1}{q(\theta)+\lambda}\left[\begin{array}{c}
\left(1-F_{E}(T)\right) . l .(1-u) \\
+(j c r+\lambda . v)(1-F(T))
\end{array}\right]
\end{aligned}
$$




\section{Appendix C}

This appendix gives a sketch of explanation as to why wages of employed job seekers are much more affected by a change in the surplus, caused for example by a change in the unemployment benefit, than wages of employed individuals who do not search. From the Bellman equations (2) and (1), we have:

$$
\begin{aligned}
& \frac{\partial\left(E_{o}-U\right)}{\partial w_{o}}=\frac{1}{r+l+a \theta q(\theta)+\lambda} \\
& \frac{\partial\left(E_{n}-U\right)}{\partial w_{n}}=\frac{1}{r+l+\lambda}
\end{aligned}
$$

With the parameter values of our base case, this means that to induce a given change in the worker's side of the surplus the wage of employed job seekers needs to adjust by $\frac{r+l+a \theta q(\theta)+\lambda}{r+l+\lambda}=4.6$ times as much as the wage of individuals who do not search. Hence, following a rise in unemployment benefit, as in section 3.5 , wages in the range $(R ; S)$, i.e.in the bottom of the wage distribution, where employed individuals search on the job, exhibit a much larger rise than wages in the rest of the wage distribution, where employed workers do not search. This then leads to a compression of the wage distribution, reinforced by the fact that the range of viable productivities is narrower when the unemployment income is raised. 


\section{References}

[1] Balakrishnan, R. and Michelacci, C. (2001), 'Unemployment dynamics across OECD countries', European Economic Review, vol. 45, pp. 135-165.

[2] Balmaseda, M., Dolado, J.J. and Lopez-Salido, D. (2000), 'The dynamic effects of shocks to labour markets: evidence from OECD countries', Oxford Economic Papers, vol. 52, pp. 3-23.

[3] Blanchard, O. and Diamond, P. (1989), 'The Beveridge curve', Brookings Papers on Economic Activity, pp. 1-60.

[4] Blau, D. and Robins, P. (1990), 'Job search outcomes for the employed and unemployed', Journal of Political Economy, vol. 98, pp.637-655.

[5] Boeri, T. (1996), 'Is job turnover countercyclical?', Journal of Labor Economics, vol. 14, pp. 603-625.

[6] Boeri, T. (1999), 'Enforcement of employment security regulations, on-thejob search and unemployment duration', European Economic Review, vol. 43 , pp. $65-89$.

[7] Bontemps, C. Robin, J.-M. and van den Berg, G. (1999), 'An empirical equilibrium job search model with search on the job and heterogeneous workers and firms', International Economic Review, vol.40, pp.1039-1074.

[8] Burda, M. and Wyplosz, C. (1994), 'Gross worker and job flows in Europe', European Economic Review, vol. 38, pp. 1287-1315.

[9] Burdett, K. and Mortensen, D. (1998), 'Wage differentials, employer size and unemployment', International Economic Review, vol. 39, pp. 257-273.

[10] Burgess, S. (1993), 'A model of competition between employed and unemployed job searchers: An application to the unemployment outflow rate in Britain', Economic Journal, pp. 1190-1204.

[11] Burgess, S. Lane, J. and Stevens, D. (2000) 'Job flows, worker flows and churning', Journal of Labor Economics, vol. 18, pp. 473-502.

[12] Burgess, S. and Turon, H. (2000), 'Unemployment dynamics, duration and equilibrium: Evidence from Britain', CEP Working Paper \# 474.

[13] Contini, B. and Revelli, R. (1997), 'Gross flows vs. net flows in the labor market: What is there to be learned?', Labour Economics, vol. 4, pp. 245263.

[14] Costain, J. and Reiter, M. (2003), 'Business cycles, unemployment insurance, and the calibration of matching models', mimeo.

[15] Davis, S. and Haltiwanger, J. (1992), 'Gross job creation, gross job destruction and employment reallocation', Quarterly Journal of Economics, pp. 819-863.

[16] Den Haan, W., Haefke, C. and Ramey, G. (2001), 'Shocks and institutions in a job matching model', NBER Working Paper \# 8463.

[17] Den Haan, W., Ramey, G. and Watson, J. (2000), 'Job destruction and the propagation of shocks', American Economic Review, vol. 90, pp. 482-498. 
[18] Dolado, J .J., Jansen, M., and Jimeno, J.F. (2003), 'On-the-job Search in a Matching Model with Heterogeneous Jobs and Workers', mimeo, Universidad Carlos III, Madrid.

[19] Eriksson, S. and Gottfries, N. (2002), 'Ranking of job applicants, on-thejob search and persistent unemployment' Working Paper Series, Uppsala University, Department of Economics.

[20] Fuentes, A. (2002) 'On-the-job search and the Beveridge curve', IMF Working Paper.

[21] Galindo-Rueda, F. (2002) 'Endogenous wage and capital dispersion, onthe-job search and the matching technology', IZA Discussion Paper \#625.

Garibaldi, P. and Wasmer, E. (2001), 'Labor market flows and equilibrium search unemployment', IZA discussion paper \# 406.

[22] Hall, R. (2003) 'Wage determination and employment fluctuations', mimeo.

[23] Hosios, D. (1990), 'On the efficiency of matching and related models of search and unemployment', Review of Economic Studies, vol. 62, pp. 279298 .

[24] Jovanovic (1979), 'Job matching and the theory of turnover', Journal of Political Economy, vol. 87, pp. 972-990.

[25] Kugler, A. and Saint-Paul, G. (2003) 'Hiring and firing costs, adverse selection and long-term unemployment', Journal of Labor Economics, forthcoming.

[26] Lane, J. Stevens, D. and Burgess, S. (1996) 'Worker and job flows', Economics letters, vol. 51, pp. 109-113.

[27] Layard, R. Nickell, S. and Jackman, R. (1991) 'Unemployment: macroeconomic performance and the labour market', Oxford University Press, Oxford.

[28] Merz, M. (1999), 'Heterogeneous job-matches and the cyclical behavior of labor turnover', Journal of Monetary Economics, vol. 43, pp. 91-124.

Mortensen, D. (1994), 'The cyclical behaviour of job and worker flows', Journal of Economic Dynamics and Control, vol. 18, pp. 1121-1142.

[29] Mortensen, D. and Pissarides, C. (1994), 'Job creation and job destruction in the theory of unemployment', Review of Economic Studies, vol. 61, pp. 397-416.

[30] Mortensen, D. and Pissarides, C. (1999a), 'Job reallocation, employment fluctuations and unemployment' in Handbook of Macroeconomics by J. Taylor and M. Woodford (eds), vol. 1, pp. 1137-1170.

[31] Mortensen, D. and Pissarides, C. (1999b), 'New developments in models of search in the labor market' in Handbook of Labor Economics by $\mathrm{O}$. Ashenfelter and D. Card (eds), vol. 3, pp. 2567-2627.

[32] Nickell, S. (2002), 'A picture of job insecurity facing British men', Economic Journal, vol. 112, pp. 1-27. 
[33] Pissarides, C. (2000), 'Equilibrium unemployment theory', Blackwell, Oxford.

[34] Pissarides, C. (1994), 'Search unemployment with on-the-job search', Review of Economic Studies, vol. 61, pp. 457-475.

[35] Pissarides, C. and Wadsworth, J. (1994), 'On-the-job search - some empirical evidence from Britain', European Economic Review, vol. 38(2), pp. 385-401.

[36] Postel-Vinay, F. and Robin, J.M. (2002), 'Equilibrium wage dispersion with worker and employer heterogeneity', Econometrica, vol. 70, pp. 2295-2350.

[37] Shimer, R. (2005), 'The cyclical behavior of equilibrium unemployment and vacancies: evidence and theory', American Economic Review, forthcoming

[38] Shimer, R. (2003), 'Dynamics in a model with on-the-job search', mimeo.

[39] Shimer, R. (2004), 'On-the-job search, bargaining, and wage dispersion', mimeo. 